\title{
Características de Fusão e Potência de Soldagem com a Transferência MIG - CMT versus MIG convencional para Alumínio 5183
}

\author{
(Melting and Welding Power Characteristics of MIG CMT versus Conventional MIG for Aluminum 5183)
}

\author{
Jair Carlos Dutra ${ }^{1}$, Régis Henrique Gonçalves e Silva², Cleber Marques ${ }^{3}$ \\ ${ }^{1,2,3}$ Universidade Federal de Santa Catarina, Departamento de Engenharia Mecânica, Laboratório de Soldagem, Florianópolis, Santa \\ Catarina,Brasil,jdutra@labsolda.ufsc.br ${ }^{1}, r e g i s @ l a b s o l d a . u f s c . b r^{2}$, cmarques@labsolda.ufsc.br ${ }^{3}$
}

\begin{abstract}
Resumo
De todos os processos de soldagem a arco, o MIG/MAG é o que recebe maior número de inventivas, originando uma quantidade enorme de novas versões. Em virtude disto, surge uma grande dificuldade dos usuários em manterem-se atualizados no estado da arte e de tomarem as devidas decisões, seja na seleção de novos equipamentos, seja na seleção da correta modalidade e respectiva regulagem dentro de um equipamento já disponível. Muitas das novidades vêm ao mercado com uma roupagem tecnológica que nem sempre está muito próxima da verdade científica. Assim, este artigo se propõe a dar uma contribuição a esta questão, abordando a versão CMT (Cold Metal Transfer). É apresentado um estudo das características de fusão, comparando-o com o MIG convencional no caso particular da soldagem com arame de alumínio naval 5183. Os resultados revelam que a aparente baixa potência elétrica desta versão transparecida pelos baixos valores de tensão e corrente média, não é correta. Realmente, para as condições ensaiadas, ela é uma versão de processo MIG com maior potência do que o MIG convencional, quando os procedimentos de cálculo são os corretos. Apesar disso, o CMT se revela uma boa solução para a soldagem de raiz de alumínio devido à adequada cadência e repetitividade da transferência de gotas. A cadência da corrente e da tensão revela uma grande similitude com uma corrente pulsada de onda retangular, mas dentro da faixa de transferência por curto-circuito.
\end{abstract}

Palavras-chave: Potência de soldagem, Cold Metal Transfer (CMT), MIG convencional.

\begin{abstract}
Among all arc welding processes, MIG/MAG is the one experiencing most of the innovations, originating an enormous quantity of new versions. Due to this fact, end users are faced with a great difficulty in keeping up to date with the state of the art and taking due decisions, whether in the selection of new equipment or in the selection of the correct welding mode and respective adjusting of an already available equipment. Many of the novelties come on the market with a technological appeal that not always correspond to scientific truths. Thus, this paper aims at giving a contribution to this question, addressing the CMT (Cold Metal Transfer). A study of melting characteristics is presented, providing comparisons with the conventional short-circuiting MIG/MAG process for the particular case of naval aluminum 5183. Results reveal that the apparent low electrical power of the CMT, suggested by the low average voltage and current, is not correct. Indeed for the adopted conditions it is a variant of the MIG/MAG process with more power than conventional MIG/MAG, when correct power calculation procedures are made. Nevertheless CMT proves itself as good solution for aluminum root pass welds due to the adequate cadence and droplet transfer repeatability. The current and voltage cadence shows a great similarity with a rectangular pulsed wave, but inside a short-circuiting transfer range.
\end{abstract}

Key-words: Welding power, Cold Metal Transfer (CMT), conventional MIG

\section{Introdução}

Apesar de ter surgido há mais de seis décadas, o processo de soldagem MIG/MAG continua a gerar sempre novas expectativas e tem sido continuamente assunto de pauta. Para um leigo, ao examinar o conjunto do processo, o mesmo se parece como nos seus primórdios. Entretanto, as inserções tecnológicas são de tal ordem e diversidade, que, se não fosse pela similitude das

(Recebido em 29/02/2012; Texto final em 08/08/2012). partes macro componentes, teriam surgido mais de uma dezena de novas designações para diferenciá-lo daquele que surgiu há tanto tempo. Esta profusão de inovações tem como causa o aumento da importância que a tecnologia da soldagem obteve em relação aos demais processos de fabricação e o processo $\mathrm{MIG} / \mathrm{MAG}$ é aquele que oferece as maiores chances de receber inovações. Entretanto, o que permitiu este desenvolvimento foram invenções em vários ramos da ciência e tecnologia, as quais envolvem a eletrônica de controle, a eletrônica de potência, a informática e os sistemas de acionamento. Em consequência, inúmeras empresas espalhadas pelo mundo lançam no mercado a cada ano um grande número de novidades, anunciando soluções e objetivos, que deixam o usuário bastante aturdido. De fato, as 
explicações para grande parte dos resultados obtidos não refletem adequadamente a realidade científica. As verdadeiras razões para que uma determinada tecnologia seja boa são mascaradas por frases de efeito mercadológico. Isto, para a ciência, se torna um desserviço grave e, por esta razão, os laboratórios e institutos de pesquisa devem exercer com bastante empenho sua ação. É neste contexto que se insere o presente trabalho, que se propõe a dar uma contribuição na análise e avaliar o que há de diferente no processo com transferência metálica por curto-circuito controlado denominado CMT - Cold Metal Transfer.

\section{Fundamentação}

Após a sua invenção nos idos de 1940, o processo MIG/ MAG permaneceu por muito tempo sendo utilizado com fontes comandadas em tensão, já que era a maneira possível para que o processo funcionasse na faixa onde a transferência metálica ocorre por curto-circuito. Nesta faixa de operação e para as fontes de soldagem convencionais, o arco não tem condições de permanecer aceso continuamente, uma vez que a velocidade de fusão não é suficiente para evitar o contato físico do eletrodo com a peça. Neste caso, a corrente não pode permanecer fixa, pois, do contrário, a gota metálica formada no extremo do eletrodo não se destaca, fazendo com que o eletrodo adira à peça e o arco não tenha condições de reacender. Desse modo, nos sistemas convencionais, a corrente tem de estar livre para variar a fim de que a cada curto-circuito o arco possa se restabelecer, propiciando a continuidade do processo. A Figura 1 ilustra para a situação de velocidade de arame (Va) abordada neste trabalho, como as variáveis, tensão, corrente e potência do arco se comportam. Nestes sistemas, apenas a dinâmica com que a corrente varia pode ser regulada. Esta regulagem é, nas fontes de soldagem, conhecida por indutância. Por seu intermédio, podem ser obtidos resultados melhorados para várias combinações de variáveis de soldagem, como é tratado em vários trabalhos [1] [2]. Mesmo com estas regulagens, o sistema é baseado no fato que a corrente se adapta às circunstâncias dos fenômenos e é a isto que se denomina de auto adaptação ou de "Controle Interno".

Se a fonte fosse de corrente constante, quando houvesse o curto-circuito e consequente extinção do arco, não haveria dinâmica adequada para a sua reabertura. A gota no extremo do eletrodo teria dificuldade de ser expelida e o arame, em continuando sendo alimentado, não ofereceria condições para o ressurgimento do arco. Entrementes, há que se fazer menção aqui ao sistema de controle desenvolvido certo tempo depois [3] [4], que tinha o objetivo de controlar a velocidade do arame-eletrodo por meio da monitoração da tensão de soldagem. Este sistema é denominado de controle externo, numa tentativa de diferenciar do sistema convencional com fonte de tensão constante (controle interno). Entretanto, o controle externo só funcionava razoavelmente quando a faixa de transferência metálica não era a de curto-circuito. A simples parada do arame no ato do curtocircuito, sem que houvesse um aumento da corrente para expelir a gota e reabrir o arco, não produzia continuidade ao processo, principalmente em posições diferentes da plana.

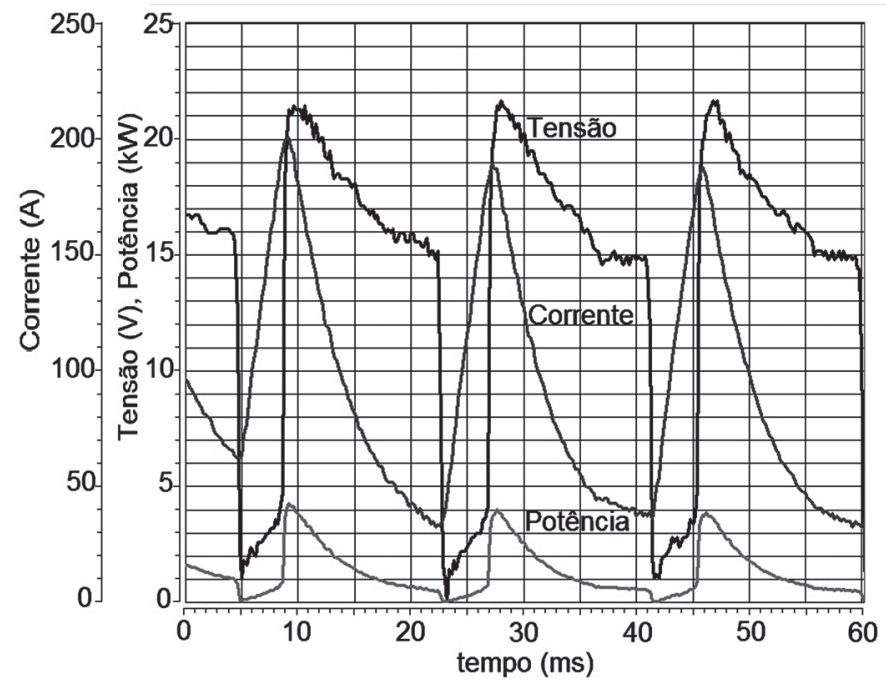

Figura 1. Oscilogramas de tensão, corrente e potência para o modo MIG convencional.

Toda esta problemática citada é alterada com o advento dos sistemas em malha fechada com o objetivo de controlar a corrente. Estas novas tecnologias de fontes de soldagem não são mais de comando em tensão (tensão constante), mas sim, são comandadas em corrente (em alguns casos, um misto de corrente e tensão). Isto significa que o comportamento da corrente no evento do curto-circuito é devidamente controlado a partir da monitoração do arco e da poça de fusão. Trata-se, em princípio, de uma corrente pulsada, embora não seja assim denominada porque está convencionado que o termo pulsado no processo $\mathrm{MIG} / \mathrm{MAG}$ fica restrito ao caso da transferência metálica sem curto-circuito. A versão CMT (Cold Metal Transfer) do processo MIG/MAG, além de controlar a forma da onda da corrente, controla a velocidade e sentido de avanço do arame (de acordo com a frequência de transferência, por intermédio de um motor posicionado na tocha) e, de maneira análoga ao que se tem no sistema convencional do denominado controle externo, a velocidade do arame no cabeçote alimentador. Entretanto, a dinâmica da corrente, da tensão e da potência, conforme oscilogramas da Figura 2, para uma situação de velocidade de arame idêntica ao do MIG convencional (Figura 1), mostra claramente fases muito mais distintas. A tensão no curtocircuito permanece em um patamar muito baixo durante toda esta fase, que é de cerca de $10 \mathrm{~ms}$, ao mesmo tempo em que a corrente também permanece em praticamente 30 A durante toda a referida fase. Em consequência a potência elétrica na mesma é extremamente baixa e constante. Quando o arco reacende, a corrente, após um curto tempo em valor baixo, é controlada em um patamar praticamente constante e relativamente alto em aproximadamente $68 \%$ do período total. A tensão assume também valores altos que não são substancialmente diferentes dentro do referido tempo. Isto conduz a uma potência resultante consideravelmente alta e praticamente constante, surgindo condições de formar uma gota de maneira muito rápida. Dessa forma, o processo pode ser bem caracterizado como sendo intercalações de "quente e frio" [5], mas não necessariamente 
um processo "frio" em seu conjunto, como seu nome sugere.

Esta combinação de potência alta e baixa é como se fosse uma corrente pulsada de onda retangular e, com a associação do retrocesso do arame, propicia uma transferência de gota metálica por tensão superficial de maneira muito suave, estável e regular [6] [7]. Essa tecnologia também se mostra eficaz na redução de respingos.

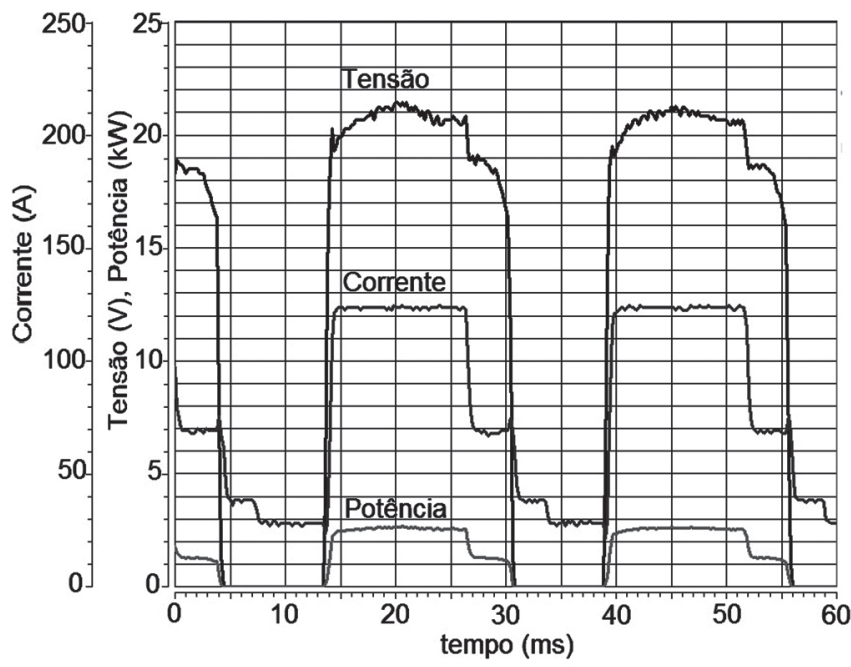

Figura 2. Oscilogramas de tensão, corrente e potência para o modo CMT.

\section{Determinação das Características de Fusão da Versão CMT em relação ao convencional}

Com o objetivo de analisar o comportamento de fusão do alumínio no CMT foi iniciado um estudo da soldagem do alumínio naval 5183, já que este será o metal de adição utilizado na construção de um veleiro para pesquisas oceanográficas da UFSC. O estudo teve como metodologia inicial os experimentos realizados por Kiyohara em 1979 [8] em que verificava as características de fusão do arame 5183 de 1,6 mm de diâmetro utilizando o processo MIG convencional. No caso do presente trabalho, os dados para o arame 5183 são determinados para ambos os casos, MIG convencional e CMT. A soldagem foi conduzida em simples depósitos sobre chapas. Para uma mesma velocidade de arame (Va), a tensão de soldagem foi gradativamente aumentada, e em cada situação foi medido o valor da corrente.

Para o MIG convencional foi utilizada a fonte de soldagem Digiplus do fabricante IMC Soldagem. A velocidade do arame, com 1,2 mm de diâmetro, foi fixada em $10 \mathrm{~mm} / \mathrm{s}(6,0 \mathrm{~m} / \mathrm{min})$ e a distância do bico de contato à peça (DBCP) foi fixada em $17 \mathrm{~mm}$. A tensão de soldagem foi regulada em um valor mínimo no limite da instabilidade do processo, e aumentada progressivamente em $1 \mathrm{~V}$ até a iminência de fusão do bico de contato. A velocidade de soldagem foi fixada em $10 \mathrm{~mm} / \mathrm{s}(60 \mathrm{~cm} / \mathrm{min})$ e a vazão de gás Argônio em 13 l/min. Os sinais de tensão, corrente e Va foram medidos com o Sistema de Aquisição Portátil (SAP-4) com taxa de aquisição de $5 \mathrm{kHz}$ [9].

Para o CMT foi utilizada a fonte Transpuls Synergic 3200CMT do fabricante Fronius. Neste caso, a determinação das coordenadas de tensão e corrente para uma mesma velocidade de arame não foi tão fácil de ser obtida porque o processo é sinérgico. Mesmo que a variável de entrada seja a velocidade do arame, esta depende e varia com a regulagem da correção da altura do arco, variável que equivale à regulagem de tensão. Para que todos os pontos de coordenadas tensão média versus corrente média correspondessem à mesma velocidade de arame, os ensaios foram conduzidos com medição "online" da velocidade média de arame, utilizando o SAP-4. Assim, para valores de altura do arco, que no equipamento tem faixa indicativa entre -30 a +30 com variação unitária, regulava-se Va de tal maneira que o valor real correspondesse a $6 \mathrm{~m} / \mathrm{min}$. Os resultados medidos nas duas versões MIG foram plotados no gráfico mostrado na Figura 3 e são aqui denominados de curvas de isoconsumo.

Antes de uma análise com o devido critério científico, poderse-ia concluir a partir da observação da Figura 3 que a potência elétrica do processo CMT é inferior a do MIG convencional, fato que é contestado no item análise dos resultados.

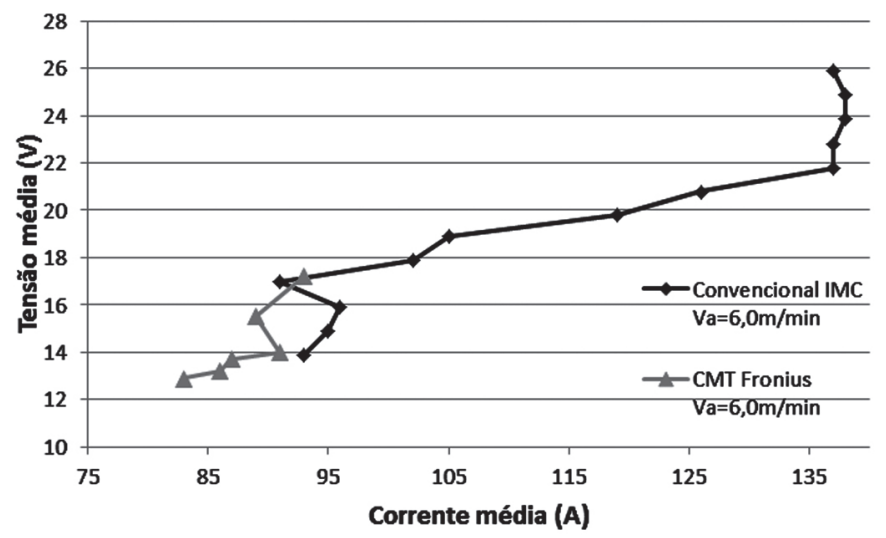

Figura 3. Curva de isoconsumo para o alumínio ER5183 com 1,2 mm de diâmetro, gás Argônio e velocidade de alimentação de arame de $0,1 \mathrm{~m} / \mathrm{s}(6,0 \mathrm{~m} / \mathrm{min})$.

\section{Experimentos de Soldagem de Raiz com a versão CMT e com o Convencional}

Para complementar a avaliação comparativa dessas variantes MIG, foram realizadas soldagens de chapas de alumínio 5083 com $6 \mathrm{~mm}$ de espessura, dispostas em junta de topo com espaçamento de $1,2 \mathrm{~mm}$, chanfro de $80^{\circ}$ na posição plana e gás argônio em 13 1/min. O critério básico para esta comparação foi permitir que o soldador buscasse um procedimento com o CMT de tal modo que conseguisse uma solda com características visuais de aceitabilidade, tanto na face como na raiz. Embora que com este processo (CMT) seja relativamente fácil a obtenção de uma raiz sem a utilização de cobre-juntas ou backing, foi adotado utilizá-lo uma vez que o objetivo destes ensaios era a comparação com o MIG convencional. Com isto, a capacidade de cada versão do processo não seria um impedimento para os ensaios comparativos em uma mesma geometria de junta. A velocidade de arame adotada pelo soldador foi de $11,7 \mathrm{~mm} / \mathrm{s}$ ( $7 \mathrm{~m} / \mathrm{min}$ ). Assim, no MIG convencional foi assumida a mesma velocidade de arame, com a tensão regulada em $14 \mathrm{~V}$. A fonte 
possibilita ainda a regulagem de duas variáveis que atuam na dinâmica de subida e descida da corrente, denominadas de Ks e $\mathrm{Kd}$, respectivamente. Para a solda realizada, os valores foram: $\mathrm{Ks}=60, \mathrm{Kd}=50 . \quad \mathrm{O}$ soldador adotou um ângulo de ataque levemente empurrando. Os resultados obtidos são verificados nas Figuras 4 e 5.

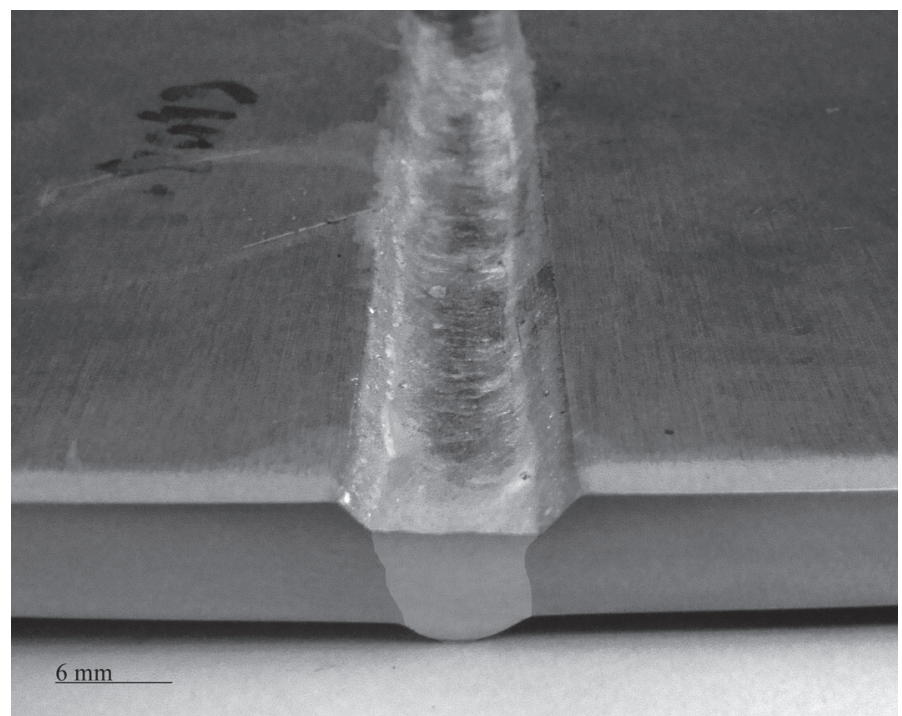

Figura 4. Solda manual de Alumínio 5083, posição plana, chapa de $6 \mathrm{~mm}$ com MIG CMT regulagem de corrente em 110 $\mathrm{A}, \mathrm{Va}_{\text {média }}=7,0 \mathrm{~m} / \mathrm{min}$.

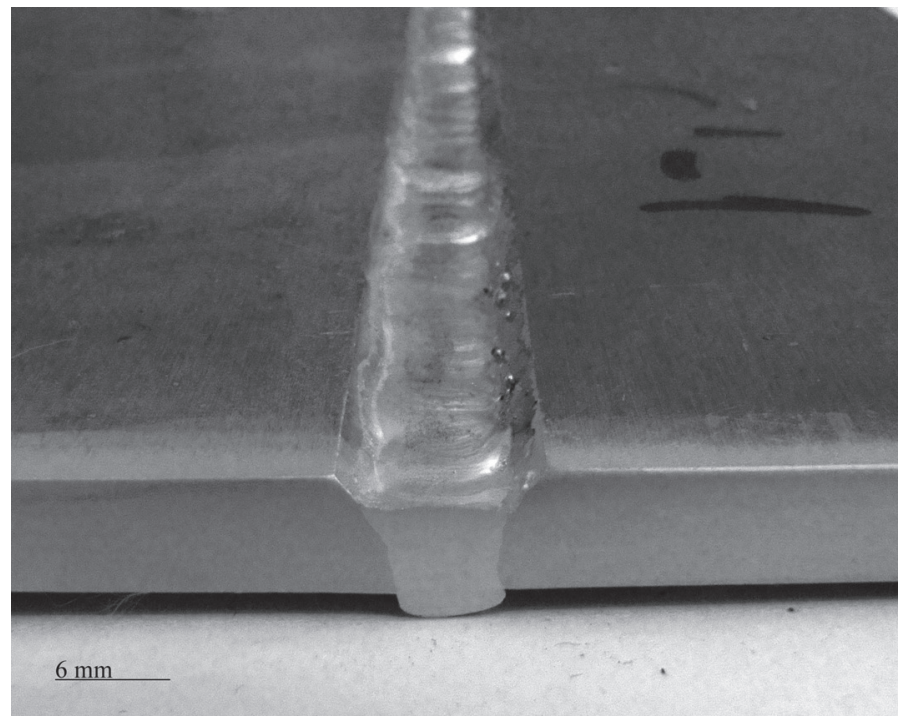

Figura 5. Solda manual de Alumínio 5083, posição plana, chapa de $6 \mathrm{~mm}$ com MIG Convencional regulagem de tensão em $14 \mathrm{~V}, \mathrm{Va}=7,0 \mathrm{~m} / \mathrm{min}, \mathrm{Ks}=60, \mathrm{Kd}=50$.

\section{Análise dos Resultados}

As curvas de isoconsumo obtidas para o modo MIG convencional e CMT (Figura 3), dispostas em um mesmo sistema de coordenadas, induzem a atribuição de uma menor potência para a curva do CMT. Os cálculos de potência revelaram o contrário, cabendo aqui fazer uma menção ao correto procedimento do cálculo da potência elétrica.

\subsection{Cálculo de Potência elétrica}

A definição de potência elétrica é o produto da tensão pela corrente. Acontece, entretanto, que frequentemente uma devida interpretação não é dada a esta definição. Algumas vezes é realizada a leitura da tensão média e da corrente média e ao produto disto é denominado de potência. Isto não é correto porque o produto das médias de duas variáveis é diferente da média dos produtos dos valores sazonais ou individuais das variáveis envolvidas. Assim, a equação 1 é errada. Outro critério, que por vezes também é adotado, é o produto da tensão eficaz pela corrente eficaz, conforme a equação 2 , o que para um processo submetido a situações dinâmicas, também é errôneo. Esta última equação somente é válida quando a carga elétrica obedecer estritamente à lei de $\mathrm{Ohm}$. $\mathrm{O}$ desvio do arco em relação à lei de Ohm é tanto maior quanto maior for a diferença entre os patamares dos valores de corrente, pois a componente da força contra-eletromotriz no arco se torna altamente pronunciada. Esta é a razão pela qual as curvas apresentadas na Figura 3 dão uma falsa impressão da potência de cada modalidade do processo.

$$
\begin{aligned}
& P=U_{\text {méd }} \times I_{\text {méd }} \\
& P=U_{\text {eficaz }} \times I_{\text {eficaz }} \\
& P=\frac{\sum_{i=1}^{n} U_{i} \times I_{i}}{n}
\end{aligned}
$$

O cálculo que considera os valores pontuais de tensão e corrente, representado pela equação 3 , é o considerado correto [10] [11]. Todos os valores de potência apresentados na sequência foram calculados sobre essa equação e revelaram que o processo CMT resulta em maior potência. Para tanto basta observar a Tabela 1.

Tabela 1. Valores médios de Tensão, Corrente e Potência,

\begin{tabular}{|c|c|c|c|c|c|}
\hline \multicolumn{3}{|c|}{ CMT FRONIUS } & & & \\
\hline $\operatorname{Um}(\mathrm{V})$ & $\operatorname{Im}(\mathrm{A})$ & $\mathrm{P}(\mathrm{W})$ & & & \\
\hline 12,9 & 83 & 1430 & \multicolumn{3}{|c|}{ Convencional IMC } \\
\hline 13,2 & 86 & 1513 & $\operatorname{Um}(\mathrm{V})$ & $\operatorname{Im}(\mathrm{A})$ & $\mathrm{P}(\mathrm{W})$ \\
\hline 13,7 & 87 & 1585 & 13,9 & 93 & 1301 \\
\hline 14 & 91 & 1601 & 14,9 & 95 & 1431 \\
\hline 15,5 & 89 & 1608 & 15,9 & 96 & 1533 \\
\hline 17,2 & 93 & 1734 & 17 & 91 & 1549 \\
\hline & & & 17,9 & 102 & 1834 \\
\hline & & & 18,9 & 105 & 1988 \\
\hline & & & 19,8 & 119 & 2371 \\
\hline & & & 20,8 & 126 & 2630 \\
\hline & & & 21,8 & 137 & 2995 \\
\hline & & & 22,8 & 137 & 3125 \\
\hline & & & 23,9 & 138 & 3293 \\
\hline & & & 24,9 & 138 & 3444 \\
\hline & & & 25,9 & 137 & 3545 \\
\hline
\end{tabular}
correspondentes às curvas de isoconsumo para o Al 5183 da

Figura 3 
Em todo o campo de tensão média (Um) abrangida pelo CMT, desde $12,9 \mathrm{~V}$ a 17,2 V, a potência deste é maior que o MIG convencional. Assim, à versão CMT não pode ser atribuído que ela seja boa porque é mais "fria" que outras, mas sim devese buscar as reais razões para que ela, em determinado contexto, possa ser considerada como melhor.

Em uma análise adequada, considerando a devida definição de potência, pode-se perceber que a fundamental razão desta aparente dicotomia está na duração dos níveis altos e baixos da corrente e da tensão. Enquanto no MIG convencional os picos de corrente de até 200 A são praticamente instantâneos, no CMT uma corrente de 125 A se mantém constante por mais de $12 \mathrm{~ms}$. Nesta mesma fase a tensão também permanece em patamares altos, resultando em uma potência alta. Após esta fase, a tensão cai drasticamente a quase zero e a corrente assume valores próximos a $30 \mathrm{~A}$. Assim, nessa etapa a potência é praticamente zero. Nesta primeira abordagem, poder-se-ia concluir que o CMT conduziria a uma baixa potência, já que os pulsos de corrente são mais baixos que no MIG convencional e também a potência nos curtos-circuitos é muito baixa. Além disso, pode-se adicionar a isto os tempos relativos de curto-circuito e de arco aberto. No CMT, de acordo com o oscilograma da Figura 2, o tempo de curto circuito corresponde a aproximadamente $32 \%$ do período da onda, enquanto o de arco aberto a $68 \%$. Já no MIG convencional (Figura 1), os respectivos tempos são de $24 \%$ e $76 \%$. Assim, tempos maiores de arco aberto (potência maior) relativamente aos tempos de curto-circuito (potência menor) conduziriam a afirmar que o CMT teria menor potência. Esta análise, entretanto, é equivocada e para um entendimento mais didático apresenta-se nas Figuras 6 e 7 oscilogramas idealizados a partir das situações reais das Figuras 1 e 2, tomando-se 100 pontos como se fosse aquisição de dados. Dessa forma os cálculos de potência não deixam margem a erro. A Tabela 2 mostra os valores calculados, onde se pode constatar a grande diferença entre a potência calculada de maneira correta e as consideradas frequentemente. Assim, também se pode ver que as formas de onda do CMT conduzem a uma maior potência do que o MIG convencional.

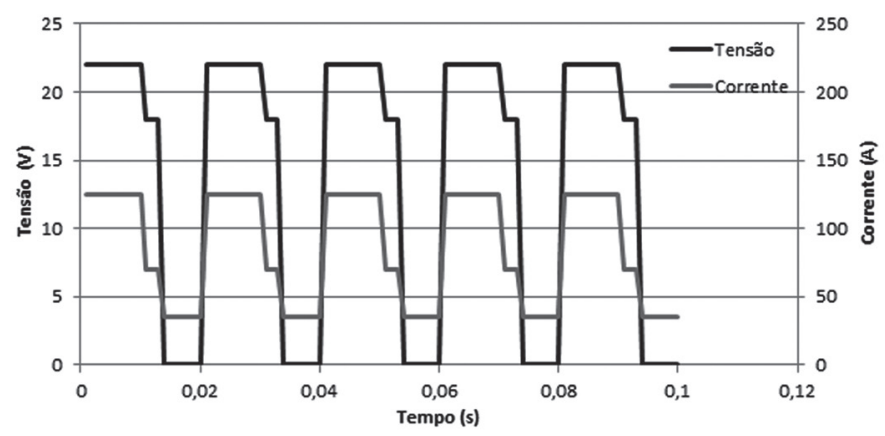

Figura 6. Oscilogramas hipotéticos de tensão e corrente para uma situação próxima ao CMT.

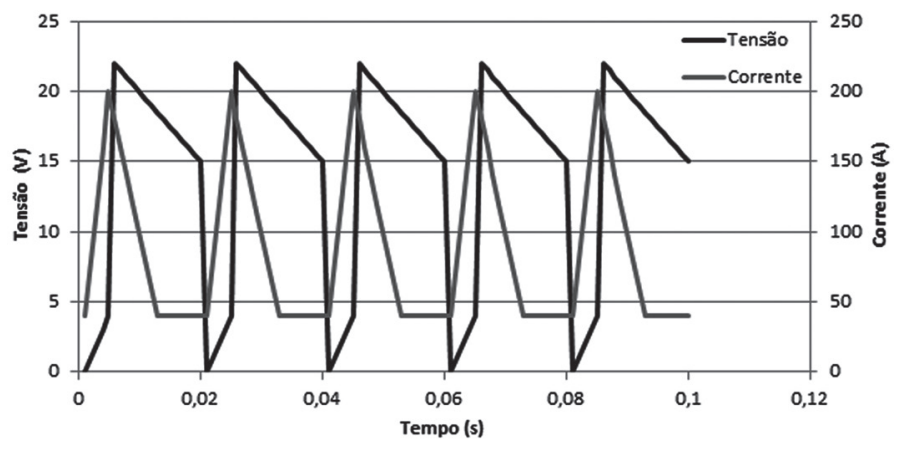

Figura 7. Oscilogramas hipotéticos de tensão e corrente para uma situação próxima ao MIG Convencional.

Tabela 2. Dados calculados para as situações hipotéticas

\begin{tabular}{|l|c|c|}
\hline & $\begin{array}{c}\text { Oscilograma } \\
\text { Figura 6 }\end{array}$ & $\begin{array}{c}\text { Oscilograma } \\
\text { Figura 7 }\end{array}$ \\
\hline Im (A) & 85,3 & 88,0 \\
\hline Um (V) & 13,7 & 14,4 \\
\hline Ief (A) & 94,7 & 103,2 \\
\hline Uef (V) & 17,0 & 16,2 \\
\hline Um x Im & 1169 & 1267 \\
\hline Uef x Ief & 1610 & 1672 \\
\hline Potência (W) & 1564 & 1223 \\
\hline
\end{tabular}

Mesmo com valores de tensão e corrente médias menores que os da Figura 7, os dados do oscilograma da Figura 6 resultaram em uma potência $27,8 \%$ maior, divergindo do simples produto de tensão e corrente, tanto em valores médios quanto eficazes, que levaria a conclusão equivocada que o oscilograma da Figura 7 produz maior potência.

\subsection{Solda de raiz}

Para a obtenção das soldas de raiz, de acordo com o que já foi descrito anteriormente, foram desenvolvidos dois procedimentos otimizados, um para cada modalidade de MIG, tendo como similitude entre eles a velocidade de arame. Os critérios de avaliação foram a facilidade do soldador em conduzir as soldas e a observação da estabilidade da transferência de gotas por meio de histogramas. Nas Figuras 8A e 8B são apresentados os histogramas para os períodos de transferência. Sem dúvida alguma o histograma para o CMT revela um processo muito mais estável, pois concentra as transferências em aproximadamente $21 \mathrm{~ms}$. O MIG convencional, embora considerado estável nesta situação, apresenta uma maior aleatoriedade dos períodos de transferência. Quanto às características de fusão, é conveniente novamente salientar que há uma sensível diferença entre as modalidades de processo. No presente caso, há uma diferença de aproximadamente $5 \%$ nas correntes médias correspondentes (Tabela 3), fato que é quase sempre negligenciado na literatura, quando são apresentadas relações diretas entre a corrente média e a velocidade de fusão dos eletrodos, sem fazer menção que tal relacionamento é particular para o ensaio em questão ou 
que a informação é apenas orientativa. No que tange à potência do processo, correspondente a uma mesma velocidade de fusão, os resultados são muito mais discrepantes em relação ao convencionalmente considerado. Pela Tabela 3 pode ser constado que o CMT resulta em 33,9\% maior potência que o MIG convencional. Por isso, deve-se fazer uma ressalva em relação ao que é também afirmado frequentemente de que a velocidade de fusão dos eletrodos não depende da tensão. Esta afirmativa só está acometida de pequeno erro dentro de uma mesma modalidade de processo, pois a tensão, em não sofrendo variações consideráveis, pode ser substituída por uma constante, aparecendo nas equações somente a variável intensidade de corrente. Quanto à qualidade dos cordões de solda, é indubitável o melhor resultado com a utilização do CMT, revelando uma aparência do lado reverso que não deixa dúvidas quanto à sua aceitabilidade. Já a raiz com o MIG convencional revela uma má aparência, deixando dúvidas quanto à sua aceitabilidade.

Tabela 3. Parâmetros adquiridos em soldagem de raiz manual, com velocidade de arame de $7 \mathrm{~m} / \mathrm{min}$.

\begin{tabular}{|l|c|c|}
\hline & CMT & $\begin{array}{c}\text { MIG } \\
\text { Convencional }\end{array}$ \\
\hline $\operatorname{Im}(\mathrm{A})$ & 105 & 112 \\
\hline Um (V) & 14,5 & 12,8 \\
\hline Potência (W) & 1946 & 1453 \\
\hline
\end{tabular}

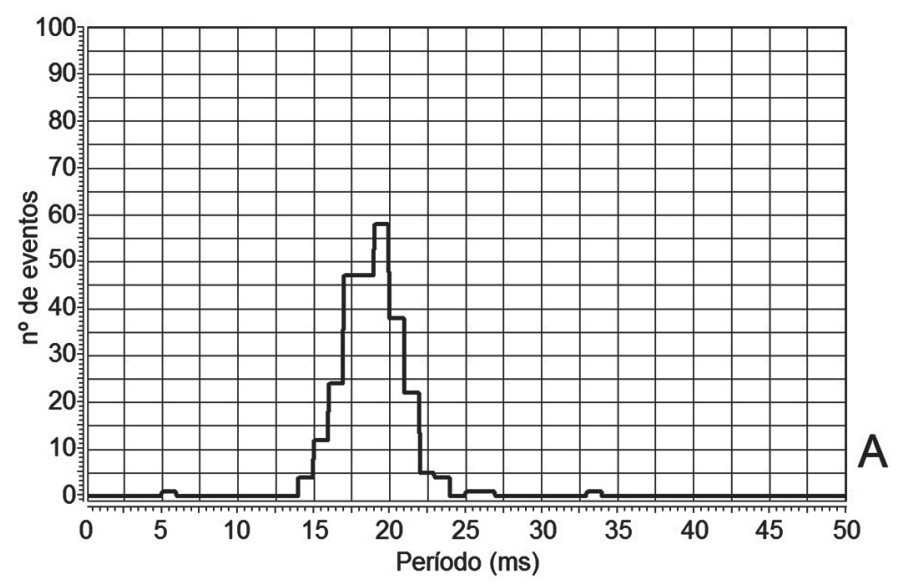

\subsection{Avaliação em termos do rendimento bruto de fusão}

De modo a se obter uma avaliação comparativa que relacione o calor aportado à peça que contribuiu para a fusão do material, foram calculados os valores de rendimento de fusão para soldagens realizadas com as duas modalidades MIG estudadas neste trabalho. De acordo com a metodologia de cálculo colocada por Reis et al [12], o cálculo do rendimento de fusão é dado pela divisão entre a quantidade de calor usada para a fusão (Qf) pela energia fornecida pela fonte (E). Como o cálculo da energia leva em consideração a velocidade de deslocamento da tocha, os resultados obtidos de forma manual não foram utilizados e novos ensaios foram realizados de forma mecanizada, garantindo assim, a mesma velocidade em todos os cordões. O cálculo de Qf utiliza, entre outros dados, o valor da área fundida, que para os cálculos em questão foi obtido com medições de macrografias da área total fundida.

Os valores médios de rendimento bruto de fusão foram obtidos com a média de três amostras de cada modalidade MIG. Para o CMT, o rendimento médio foi de $26,7 \%$ contra $33,5 \%$ para o MIG convencional. A Figura 9 mostra a secção transversal de uma amostra de cada modalidade.

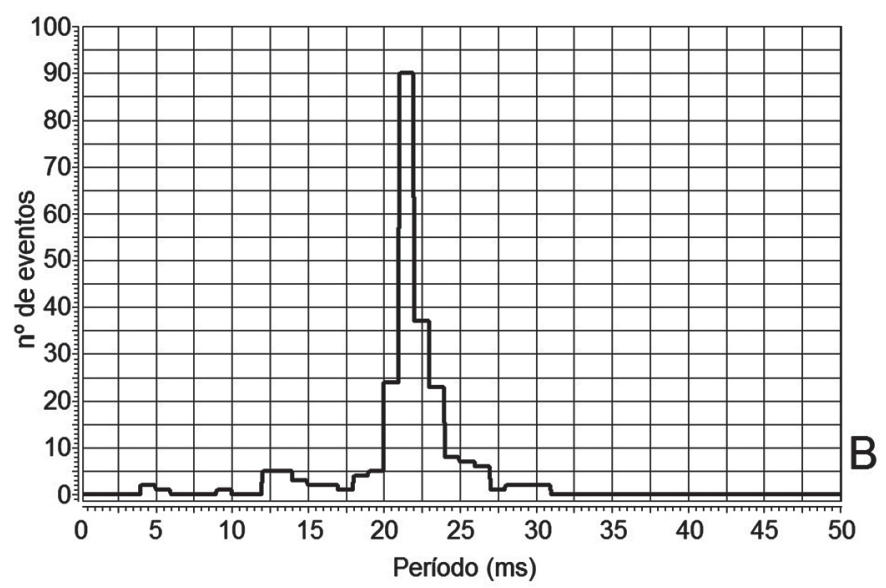

Figura 8. Histogramas dos períodos de transferência num intervalo de 5 segundos, em: A - MIG Convencional, B - MIG CMT.

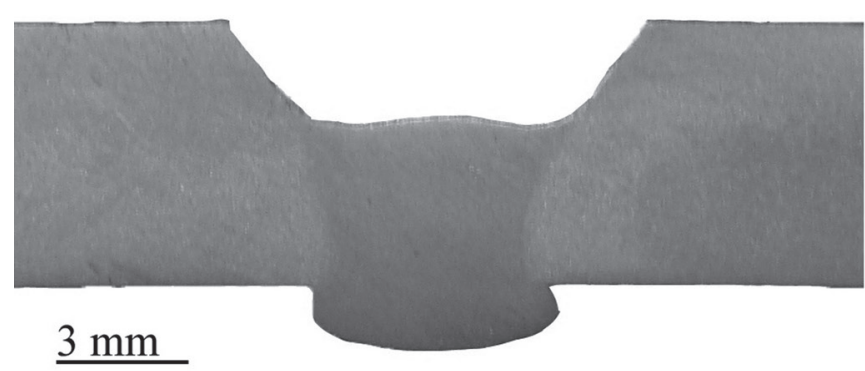

A

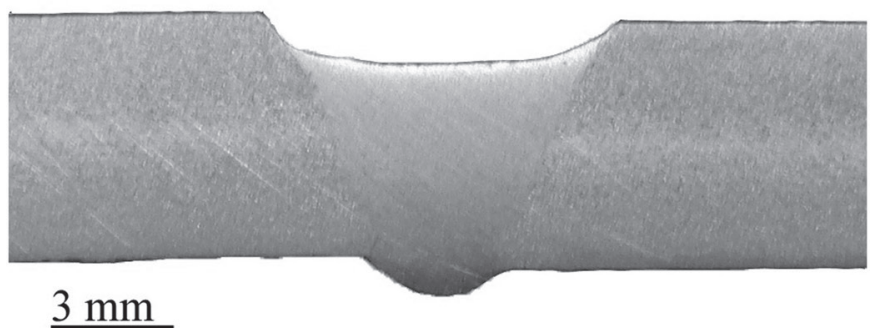

B

Figura 9. Seç̧ão transversal das soldagens mecanizadas com velocidade de soldagem $40 \mathrm{~cm} / \mathrm{min}$ e velocidade de arame $7,0 \mathrm{~m} /$ min, em: A - MIG Convencional, B - MIG CMT. 


\section{Conclusões}

Com o objetivo de se obter informações comparativas entre a versão CMT e a Convencional para a soldagem de Alumínio, foram conduzidos ensaios sob condições definidas, com critérios concretos em relação ao aspecto que, em divulgações, destaca o desempenho do CMT. Foram obtidos resultados não absolutamente óbvios em relação ao que se espera de um processo designado por "frio" (Cold Metal Transfer). Especificamente, o CMT apresentou um rendimento bruto de fusão mais baixo e maior potência de soldagem, que o MIG convencional. Portanto, foi testificado nas experiências deste trabalho que a versão CMT do processo MIG é uma boa solução tecnológica, não diretamente devido a menores potências ou maior rendimento de fusão, que poderiam advir de uma característica mais "fria" (Cold Metal Transfer), mas sim pelo fato do processo ser muito mais estável (em termos de arco e poça de fusão), devido à quase perfeita cadência entre fases de grande potência e de muito baixa potência e pelas propriedades de formação do cordão relacionadas ao estado térmico do metal de solda, resultando em ótima capacidade de preencher gaps (bridgebility). É claro que para um usuário menos crítico, o processo poderia ser considerado como frio se ele se baseasse no falso cálculo da potência por meio dos valores médios de tensão e corrente. Neste sentido, as curvas de isoconsumo da Figura 3 sugerem esta interpretação. No caso de uma soldagem de raiz, a mencionada excelente capacidade de preenchimento de gaps é de especial relevância. Uma raiz produzida por esta versão de MIG se apresenta com bom acabamento, tanto na face, como no verso da junta, sem excesso de reforço no verso da raiz.

\section{Referências Bibliográficas}

[1] DUTRA, J. C. MIG/MAG - Transferência Metálica por Curto-Circuito - Fontes de Soldagem versus Gases do Arco. Soldagem e Inspeção, São Paulo, v. 13, n. 1, p. 019-024, Jan/ Mar 2008.

[2] SOUZA, D. et al. Influência da Tensão de Soldagem e do Gás de Proteção sobre a Correlação entre Indutância e Regularidade da Transferência Metálica na Soldagem MIG/MAG por CurtoCircuito. Soldagem e Inspeção, São Paulo, Vol.16, n. 2, Abr/Jun 2011. 114-122.

[3] DUTRA, J. C. Contribuição ao Estudo da Soldagem Elétrica a Arco Voltaico sob Atmosferas de Agônio e Dióxido de Carbono. Universidade Federal de Santa Catarina, p. 58. 1976. Dissertação (Mestrado em Engenharia).

[4] DUTRA, J. C. Procedimento Computadorizado de Determinação, Seleção e Controle de Variáveis na Soldagem MIG/MAG. Universidade Federal de Santa Catarina, p. 151. 1989. Tese (Doutorado em Engenharia).

[5] BRUCKNER, J. Cold Metal Transfer Has a Future Joining Steel to Aluminum. Welding Journal, Vol.84, n. 6, Junho 2005. 38-40.

[6] LABSOLDA - UFSC. Filmagem em alta velocidade: Soldagem vertical MIG Alumínio - CMT. Disponivel em: $<$ http:// www.labsolda.ufsc.br/projetos/projetos_atuais/soldanaval_ videos.php>. Acesso em: 16 jan. 2012.
[7] PICKIN, C. G.; WILliAMS, S. W.; LUNT, M. Characterisation of the cold metal transfer (CMT) process and its application for low dilution cladding. Journal of Materials Processing Technology, Vol.211, Março 2011. 496-502.

[8] KIYOHARA, M.; YAMAMOTO, H.; HARADA, S. Melting characteristics of a wire electrode in the MIG-weldng of aluminum. Arc Physics and Weld Pool Behaviour, 1979. p. 165-175.

[9] IMC Soldagem. SAP-4 - Sistema de Aquisição Portátil. Disponivel em: <http://www.imc-soldagem.com.br/sap_4. html>. Acesso em: 03 jan. 2012.

[10] CORRÊA, M. A. Diretrizes de projeto e qualificação metrológica de sistemas de medição de grandezas elétricas em processos de soldagem a arco. Universidade Federal de Santa Catarina, p. 77. 1999. dissertação (Mestrado em Engenharia).

[11] JOSEPH, A. et al. Measurement and calculation of arc power and heat transfer efficiency in pulsed gas metal arc welding. Science and Technology of Welding and Joining, Vol. 8, n. 6, 2003. 400-406.

[12] REIS, R. P. et al. Influncia do material de base sobre o rendimento de fusão em soldagem a arco. Soldagem e Inspeção, São Paulo, v. Vol.16, n. 4, p. 396-376, Out/Dez 2011. 